\title{
Features of gonadal dysgenesis and Leydig cell impairment in testes with Sertoli cell-only syndrome
}

\author{
Daria Adamczewska, Jolanta Slowikowska-Hilczer, Katarzyna Marchlewska, \\ Renata Walczak-Jedrzejowska
}

Department of Andrology and Reproductive Endocrinology, Medical University of Lodz, Lodz, Poland

\begin{abstract}
Introduction. There is evidence that disturbed spermatogenesis is associated with impaired Leydig cell function and that it may be the result of testicular dysgenesis during fetal/infant development. Sertoli cell-only syndrome (SCOS) is defined by complete lack of germ cells in the seminiferous epithelium. The pathogenesis of SCOS is still not well understood. The aim of the study is to evaluate testes with SCOS focusing on morphometric signs of testicular dysgenesis and markers of Leydig cell (LC) function in relation to hormonal status of studied infertile men.

Materials and methods. Forty-nine testicular biopsies of patients with SCOS and 15 controls with normal spermatogenesis (NOR) were studied. In each biopsy the seminiferous tubule diameter (STD), thickness of tubular membrane (TM), area fraction of intertubular space (AFIS) were measured and semi-quantitative assessment of the LC number was performed (LC-score). The results of histological examination were correlated with serum levels of FSH, LH, testosterone (T) and T/LH ratio.

Results. In SCOS group testicular volume (median [M]: 16.0 vs. 29.5; p < 0.001) and STD (M: $141.7 v s .190 .2$; $\mathrm{p}<0.001$ ) were lower, while TM (M: 9.8 vs. 6.4; $\mathrm{p}<0.001$ ) and AFIS (M: 47.6 vs. 27.6; $\mathrm{p}<0.001$ ) were significantly higher in comparison to NOR group. LC-score was higher in SCOS than in NOR group (M: 2.2 vs. 1.1; $\mathrm{p}<0.001$ ). Abnormal AFIS and STD were present in $43 \%$ of SCOS biopsies and among them in $81 \%$ the increased LC-score was found. In SCOS group, the subjects had significantly higher levels of both gonadotropins (FSH, M: 19.9 vs. 3.4; $\mathrm{p}<0.001 ; \mathrm{LH}, \mathrm{M}: 7.1$ vs. 4.2; $\mathrm{p}<0.001)$. Total serum testosterone level did not differ between studied groups; however, T/LH ratio was significantly lower in SCOS group (M: $2.3 v s .3 .8 ; \mathrm{p}<0.001$ ). Negative correlation between LC-score and STD was observed in SCOS group $(r=-0.48 ; p<0.001)$. AFIS correlated positively with serum FSH level in NOR $(r=0.53 ; p<0.05)$ and SCOS $(r=0.41 ; p<0.05)$ group, while with $\mathrm{LH}$, and negatively with T/LH ratio, only in SCOS $(\mathrm{LH}, \mathrm{r}=0.37 ; \mathrm{p}<0.05 ; \mathrm{T} / \mathrm{LH}, \mathrm{r}=-0.36 ; \mathrm{p}<0.05)$ group. Conclusions. We have shown that substantial number of testes from subjects with SCOS presented abnormal morphometric features, which are recognized as the signs of testicular dysgenesis. Additionally, an increased number of Leydig cells simultaneously with abnormal T/LH ratio were found, which suggests an impaired function of these cells. Increased serum levels of LH and also FSH, may reflect dysfunction of Leydig cells. It seems that reproductive hormones levels reflect also the condition of testicular structure, and that FSH may be related to the changes in intertubular space area independently of impaired Leydig cell function. (Folia Histochemica et Cytobiologica 2020, Vol. 58, No. 2, 73-82)
\end{abstract}

Key words: Sertoli cell-only syndrome; testicular dysgenesis syndrome; Leydig cells; FSH; LH; testosterone; testicular biopsy; histology; morphometric assessment 


\section{Introduction}

Infertility is a problem that affects approximately $15 \%$ of couples trying to conceive after at least one year of regular, unprotected intercourses. The male factor is believed to contribute alone or in combination with female factor to difficulties in achieving pregnancy in $50 \%$ of cases [1]. Male infertility can be caused by wide range of conditions identified at pre-testicular, testicular and post-testicular level. It can results from anatomical or genetic abnormalities, endocrine, systematic or neurological diseases, infections, trauma, iatrogenic injury or gonadotoxins [2]. Also other factors such as excessive oxidative stress, improper lifestyle habits and sperm DNA fragmentation have been recently extensively studied as one of the mechanisms of male infertility [3-5].

The most severe form of human male infertility is Sertoli cell-only syndrome (SCOS), sometimes called germinal aplasia, a condition that is defined by a complete lack of germ cells, but preserved Sertoli cells in the seminiferous tubules [6]. It is estimated that about $5-10 \%$ of infertile men may have SCOS; however, its incidence may reach $39 \%$ in patients with non-obstructive azoospermia (NOA) [7]

The pathogenesis of the syndrome is still not well understood. Presumably, in congenital germ cell aplasia, primordial germ cells do not migrate from the yolk sac into embryonic gonad $[8,9]$. The SCOS may also result from factors damaging spermatogenic epithelium such as toxic exposure, including chemotherapy, irradiation or hormonal factors. Cryptorchidism or viral orchitis have also been associated with the appearance of SCOS [6, 10]. Among genetic factors the most frequent are chromosomal abnormalities (e.g. Klinefelter syndrome) as well as deletions in AZF (azoospermia factor) region of the Y chromosome [11].

It is well recognized that significant proportion of patients with SCOS had elevated levels of follicle stimulating hormone (FSH) [7, 12]. However, in some cases FSH concentrations are within normal range what may indicate selective malfunction of seminiferous tubules [13]. Usually, the patients present normal levels of luteinizing hormone ( $\mathrm{LH}$ ) and testosterone (T), but some of them may present a decreased T/LH ratio resulting from slightly increased $\mathrm{LH}$ level and low-normal or decreased T level [7, 12, 14]. As hormone levels do not always distinguish normal testicular function from impaired spermatogenesis, the final diagnosis can be made only by testicular biopsy.

In cases of primary SCOS seminiferous tubules may have only slightly reduced diameter and normal tubular wall thickness. Contrary, in cases of secondary (acquired) SCOS, the tubular wall may be thickened, the seminiferous tubules diameter reduced and Sertoli cells may show signs of degeneration [6]. Not uncommon histological feature of SCOS is increased number of Leydig cells, which together with reduced T/LH is recognized as a marker of impaired Leydig cells function $[7,12,15]$. It was shown that the $\mathrm{T} / \mathrm{LH}$ ratio might be lower in men with disturbed spermatogenesis when compared to men with normal spermatogenesis [12, $14,16]$. Additionally, the cut-off value at 2 for T/LH ratio was recently established based on data from a cohort of 127 subjects with normal spermatogenesis [16]. This Leydig cell dysfunction may reflect the lack of paracrine signals from the disturbed tubular compartment or may be a consequence of testicular dysgenesis during fetal/infant development $[14,15$, $17,18]$. Additionally, apart from increased number of Leydig cells, the morphometric features such as decreased seminiferous diameter, increased tubular wall thickness and wide intertubular space may account for the signs of disturbed testicular organogenesis (dysgenesis) [19, 20].

Although testicular biopsy is the key tool in diagnostic work-up of azoospermic men, very often the process of evaluation of testicular tissue is focused primarily on the spermatogenic compartment with poor description of intertubular space and morphometric features of testicular tubule.

The aim of this study is to evaluate testes of patients with SCOS focusing on morphometric features of testicular dysgenesis and markers of Leydig cell function in relation to hormonal status of studied infertile men.

\section{Materials and methods}

The study protocol was approved by the Bioethics Committee of the Medical University of Lodz, Poland (No. $\mathrm{RNN} / 14 / 15 / \mathrm{EC})$.

Subjects and clinical data. To this retrospective study we included 49 men (age 19.6-43.8, median 31 years) with histological diagnosis of SCOS and 15 subjects (age 23.4-38.2, median 29.5 years) with normal spermatogenesis (NOR) observed in histological analysis as controls. All subjects were diagnosed because of azoospermia in semen analysis during the period 2005-2010. The most frequent andrological finding among SCOS subjects was history of cryptorchidism $(18 \% ; 9 / 49)$. Other alterations such as atrophy of contralateral testis, testicular microlithiasis found on ultrasonography or germ cell tumor in the contralateral testis were observed in $14 \%$ of the subjects ( 7 out of 49 ).

The paraffin embedded testicular biopsies as well as the subjects' medical history were available in the Department of 
Andrology and Reproductive Endocrinology of the Medical University of Lodz. Testicular biopsies were taken in the II Department of Urology, Medical University of Lodz.

The bilateral biopsy was taken only in 5 cases. The histological pattern was consistent on both sides, thus the mean value was calculated from data obtained from histological and morphometric assessment of both testes.

Before testicular biopsy the subjects underwent physical examination and the testes volume was measured by ultrasonography. Hormonal measurements were performed in 55 subjects $(\mathrm{SCOS}=40$ and $\mathrm{NOR}=15$ ) as a part of their diagnostic workup. Serum concentrations of FSH, LH, total testosterone $(\mathrm{T})$ were determined using enhanced chemiluminescence method for VITROS ECi Immunodiagnostic System with MicroWell technology utilizing commercially available VITROS Reagent Packs for the hormones according to manufacturer instruction (Ortho-Clinical Diagnostics Johnson and Johnson, UK). Hormonal determinations were performed in the laboratory of the Clinical Hospital of Medical University of Lodz. Additionally, ratio T/LH was calculated.

None of the subjects had hypogonadotropic hypogonadism, any chronic disease, Klinefelter syndrome or history of hormonal treatment. However, the patients did not have genetic analysis of AZF deletions. Although currently AZF deletions are examined routinely, 10 years earlier they were not tested in every patient.

Tissue preparation and histological analysis. All testicular biopsies were handled at the histological laboratory of the Department of Andrology and Reproductive Endocrinology, Medical University of Lodz. The subjects tissue samples were fixed in Bouin's solution, embedded in paraffin, cut at $5 \mu \mathrm{m}$-thick serial sections and transferred onto microscopic slides. After dewaxing and rehydration, the sections were stained with hematoxylin and eosin.

Histological analysis of spermatogenesis included a qualitative and quantitative evaluation of seminiferous epithelium in 50 tubules and calculation of the modified Johnsen Score (JS) was performed to confirm the histological pattern of complete SCOS and NOR in the biopsies.

Morphometric analysis. Morphometric measurements of seminiferous tubules diameter (STD), the thickness of tubular membrane (TM) as well as the areal fraction of the biopsy occupied by intertubular space (AFIS) were performed with utilization of an image analysis system. The system consists of an Eclipse E600 light microscope with a connected camera Nikon DS-Fi1c and software NIS-Elements AR Ver. 3.2 for image analysis (Nikon, Tokyo, Japan). Slides were viewed and documented at $100 \times$ and $200 \times$ total magnification (objective $10 \times$ ).

The measurements of STD and TM were performed in tubules with a circular shape. For each tubule the length of two diameters was measured. Measurements were taken

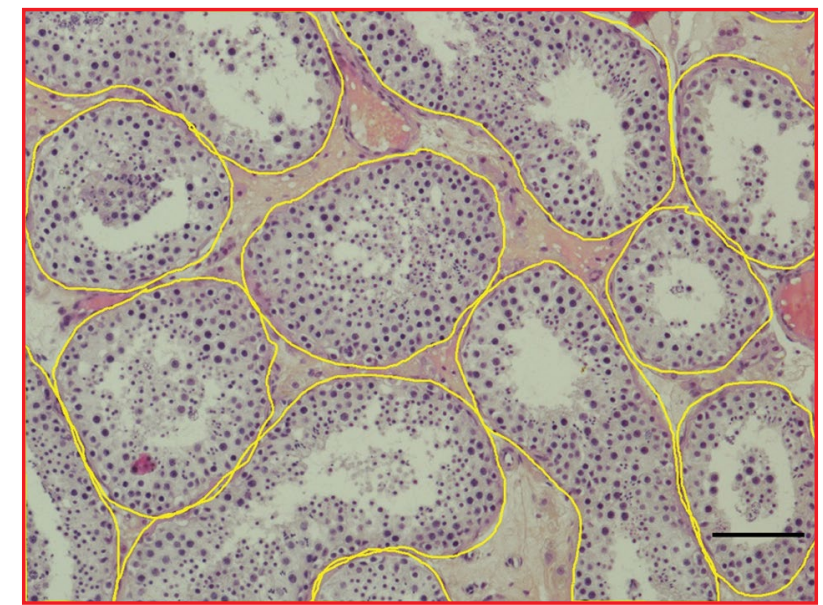

Figure 1. Seminiferous tubule delineation in a testis biopsy from the control group. The image shows seminiferous tubules cross-sections outlined in yellow using NIS-Elements AR ver. 3.2 software (Nikon). The frame used to cover the specific area of testis cross-section is marked in red and corresponds to $567240 \mu \mathrm{m}^{2}$ of the microscopic image. Magnification $100 \times$, scale bar $-100 \mu \mathrm{m}$.

from 25 tubules for each testis, at $200 \times$ magnification, and then the mean value was calculated.

To measure AFIS, the microscopic image of the biopsy was visualized on a computer screen where, with the use of an image analysis software, a standardized frame of a known size was placed. The size of the frame was $870 \times 652 \mu \mathrm{m}$ which corresponds to an area of $567240 \mu \mathrm{m}^{2}$ covered in the microscopic image of the biopsy at a $100 \times$ magnification. For each testicular biopsy an area of every single seminiferous tubule or its part present inside the frame was manually delineated (Fig. 1). The total area of intertubular space (IS) was then calculated by subtraction of the total area of seminiferous tubules from the frame area. In each case the data were collected from 10 images per each slide which corresponds to analyzed area of $5.7 \mathrm{~mm}^{2}$. Finally, the AFIS was calculated as a percentage of the analyzed biopsy area occupied by IS.

The normal values of STD, TM and AFIS were defined upon the data of previous studies [19, 21, 22]. The following values were recognized as parameters of testicular dysgenesis: STD $<150 \mu \mathrm{m}, \mathrm{TM}(>10 \mu \mathrm{m})$ and AFIS $(>40 \%)$.

Assessment of Leydig cells. Semi-quantitative assessment of Leydig cells number was performed by scoring created by Guminska et al. (2007) according to which a specific point value was assigned to number of Leydig cells observed in a particular IS as follow:

- 0 Leydig cells - 0 points;

- 1-5 Leydig cells - 1 point;

- 6-10 Leydig cells -2 points;

-11-30 Leydig cells - 3 points;

— > 30 Leydig cells (nodules of Leydig cells) - 4 points. 
Leydig cells, arranged both as isolated cells or clusters, were recognized by their morphological features and location in the interstitial tissue. The morphological features included: 1) eccentric, regular round or oval nucleus, usually with one or two prominent nucleoli, 2) the nucleus surrounded by abundant eosinophilic cytoplasm. The cells are usually located adjacent to the seminiferous tubules or near blood vessels.

In each biopsy specimen 100 triangular IS were evaluated and a mean number of points was calculated. Leydig cells score (LC-score) $>2$ points was considered as abnormal [21, 23].

Statistical analysis. The Statistica 13.1 software (StatSoft, Kraków, Poland) licensed by Medical University of Lodz was used for statistical analysis. To test the normality of obtained data the Shapiro-Wilk test was used. Due to a non-normal distribution of the majority of variables, non-parametric statistics were used. Medians and percentiles (2.5-97.5) were used for descriptive data. Between group differences were tested by Mann-Whitney U test. Nonparametric Spearman's rank correlation coefficient $\left(r_{s}\right)$ was used to evaluate statistical relationship between continuous variables. The value of $r_{\mathrm{s}}$ was interpreted as follows: $<0.2$ - lack of linear dependence, 0.2-0.4 - weak dependence, $>0.4-0.7-$ moderate dependence, $>0.7-0.9-$ strong dependence, $>0.9$ - very strong dependence. A p value below 0.05 was considered statistically significant.

\section{Results}

\section{Histological and morphometric analysis}

The evaluation of spermatogenesis confirmed the histological pattern of complete SCOS (JS $\leq 2)$ and NOR $(J S \geq 8)$ in our subjects biopsies. Representative microphotographs of testicular tissue from SCOS and NOR subjects are shown in Figure 2.

The data concerning subjects' age, both testicles volume, morphometric analysis and LC-score are presented in Table 1. There was no difference in age between the subjects from the studied groups. In SCOS group the testes volume as well as STD were significantly lower when compared to NOR group ( $p<0.001 ; p<0.001$, respectively). On the contrary, other morphometric features, i.e. TM and AFIS, were significantly higher $(\mathrm{p}<0.001 ; \mathrm{p}<0.001$, respectively). We found that abnormal morphometric features, which are recognized as parameters of testicular dysgenesis (STD $<15 \mu \mathrm{m}$, TM $>10 \mu \mathrm{m}$, AFIS > $40 \%$ ), were present in biopsies of $12 / 49$ SCO subjects $(25 \%)$, whereas only $3 / 49$ biopsies in this group (6\%) presented normal values. In the remaining $69 \%$ of biopsies with SCOS we found two $(15 / 49 ; 30 \%)$ or one $(19 / 49 ; 39 \%)$ abnormal morphometric features. The most frequent was STD $(31 / 49 ; 64 \%)$, then AFIS $(30 / 49 ; 61 \%)$, and the least frequent - TM (23/49;
$47 \%$ ). In the NOR group all biopsy presented normal value for all the studied morphometric parameters.

The Leydig cell score was significantly higher in SCOS group $(p<0.001)$ when compared to NOR group. The LC-score above 2 , which is consider abnormal, was present in 26/49 (53\%) of SCOS biopsies, and in none biopsy in NOR group. Moreover, larger cluster of LC (LC-score between 3 and 4 points) was observed in 18/49 of SCOS biopsies (36\%).

\section{Hormonal levels}

The hormone levels and ratios are presented in Table 2 . In SCOS group the subjects had significantly higher levels of gonadotropins in comparison to the control group (FSH, $\mathrm{p}<0.001 ; \mathrm{LH}, \mathrm{p}<0.001$ ). The total serum $\mathrm{T}$ concentration did not differ between the studied groups; however, the $\mathrm{T} / \mathrm{LH}$ ratio was significantly decreased in SCOS group $(\mathrm{p}<0.001)$. Considering the cut-off value for T/LH ratio, which was established by Lardone et al. [16], 13/40 (35\%) subjects from SCOS group had $\mathrm{T} / \mathrm{LH}<2$, and the remaining $27 / 40(65 \%)$ had $\mathrm{T} / \mathrm{LH} \geq 2$. All NOR subjects had $\mathrm{T} / \mathrm{LH} \geq 2$.

\section{Increased areal fraction of intertubular space (AFIS) and decreed seminiferous tubule diameter (STD) with concomitant appearance of increased Leydig cell score in SCOS patients}

To answer the question if increased Leydig cell number appears concomitantly with increased AFIS and decreased tubule diameter we checked the incidence of concomitant appearance of all three features in the analyzed biopsies. We found that abnormal AFIS $(>40 \%)$ and STD $(<150 \mu \mathrm{m})$ values were present in $43 \%$ of biopsies with SCOS (21/49) and among them in $81 \%$ (17/21) we found an increased LC-score $(>2)$. On the other hand, we found that normal values for both AFIS $(\leq 40 \%)$ and STD $(\geq 150 \mu \mathrm{m})$ were present in $16 \%$ (8/49) of SCOS biopsies and almost in all cases, except one, the LC-score was normal $(\leq 2)$ $(88 \% ; 7 / 8)$. In cases where AFIS value was abnormal and STD normal $(20 \%$; $10 / 49)$ we found that in only three biopsies $(30 \%$; 3/10) the LC-score was abnormal. Similar results were found in biopsies where AFIS value was normal and STD abnormal (20\%; 10/49). In biopsies of those patients the abnormal LC-score was also present in $30 \%$ of biopsies (3/10).

\section{Relationshisps between morphometric parameters and serum hormone concentrations}

Relationships between morphometric features of testicular dysgenesis and serum levels of FSH, LH, $\mathrm{T}$, as well as the parameters of Leydig cells function ( $\mathrm{T} / \mathrm{LH}$ ratio and $\mathrm{LC}$-score) are shown in Table 3. 

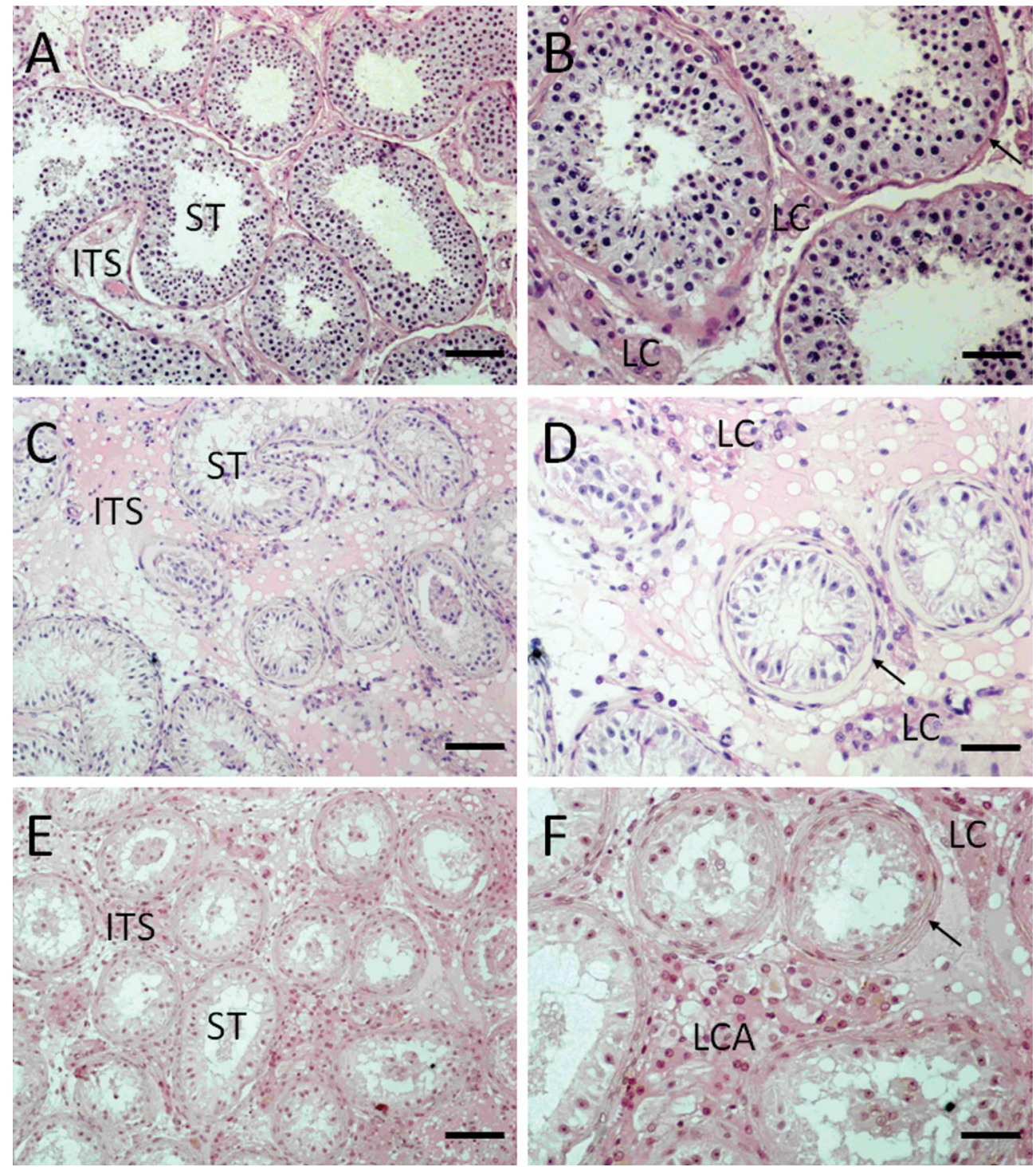

Figure 2. Histological structure of testicular biopsies from the control and SCOS group. A. Normal spermatogenesis: overview of well-developed seminiferous tubules (ST) that show a clear lumen, all stages of germ cell maturation and normal intertubular space (ITS). B. Enlargement of A: visible Leydig cells (LC) clusters of normal size; tubular basement membrane of normal thickness (arrow). C. Sertoli cell-only syndrome: overview of underdeveloped STs with small diameters; tubules contain only mature Sertoli cells, ITS is wide. D. Enlargement of C: in ITS visible LC cluster of normal size; thickness of tubular basement membrane is increased (arrow). E. Sertoli cell-only syndrome: overview of underdeveloped ST with small diameter; tubules contain only mature Sertoli cells, ITS is slightly wider than in (A). F. Enlargement of C: in ITS visible large LC cluster (aggregation) (LCA); thickness of basement membrane is increased (arrow). Magnifications and scale bars: A, C, E $-100 \times$, bar $-100 \mu \mathrm{m} ; \mathrm{B}, \mathrm{D}, \mathrm{F}-200 \times$, bar $-50 \mu \mathrm{m}$.

Considering collectively all the normal subjects and patients FSH and LH levels correlated negatively with STD $(\mathrm{p}<0.001)$ and positively with TM $(\mathrm{p}<0.001)$, AFIS $(\mathrm{p}<0.001)$ and LC-score $(\mathrm{p}<0.001)$. In SCOS group FSH and LH levels correlated positively with AFIS $(\mathrm{p}<0.05)$ and LC-score $(\mathrm{p}<0.05)$ while in NOR group the only observed correlation was between FSH levels and AFIS $(\mathrm{p}<0.05)$.
The T/LH ratio correlated positively with STD $(\mathrm{p}<0.05)$ and negatively with TM $\mathrm{p}<0.001)$, AFIS $(\mathrm{p}<0.001)$ and LC-score $(\mathrm{p}<0.01)$ when considered all the subjects. Those correlations were not observed in the NOR group while in SCOS group T/LH ratio correlated negatively only with AFIS $(\mathrm{p}<0.05)$. In all the subjects, LC-score correlated negatively with STD $(\mathrm{p}<0.001)$ and positively with AFIS $(\mathrm{p}<0.001)$ but not with TM. There were no statistically significant 
Table 1. Comparison of age, both testes volume and histological morphometric features between SCOS and NOR groups

\begin{tabular}{|l|c|c|}
\hline \multirow{2}{*}{} & \multicolumn{1}{|c|}{$\begin{array}{c}\text { } \\
\mathbf{n}=\mathbf{4 9}\end{array}$} & $\begin{array}{c}\text { NOR (control) } \\
\mathbf{n}=\mathbf{1 5}\end{array}$ \\
\cline { 2 - 3 } & \multicolumn{2}{|c|}{ Median $(2.5-97.5$ percentile) } \\
\hline Age & $31(19.6-43.8)$ & $29.5(23.4-38.2)$ \\
\hline Both testes volume $[\mathrm{mL}]$ & $\mathbf{1 6 . 0}(\mathbf{5 . 7 - 3 0 . 0})^{\mathrm{a}}$ & $30.0(22.8-40.6)$ \\
\hline Morphometry & & \\
\hline STD $[\mu \mathrm{m}]$ & $\mathbf{1 4 1 . 7}(\mathbf{9 3 . 4 - 1 8 7 . 8})^{\mathrm{a}}$ & $190.2(178.0-224.1)$ \\
\hline TM $[\mu \mathrm{m}]$ & $\mathbf{9 . 8}(\mathbf{5 . 7 - 1 7 . 5})^{\mathrm{a}}$ & $6.4(4.6-9.8)$ \\
\hline AFIS $(\%)$ & $\mathbf{4 7 . 6 ( 2 5 . 3 - 7 9 . 6})^{\mathrm{a}}$ & $27.6(20.3-39.6)$ \\
\hline LC-score (points) & $\mathbf{2 . 2}(\mathbf{1 . 0 - 4 . 0})^{\mathrm{a}}$ & $1.1(1.0-1.8)$ \\
\hline
\end{tabular}

SCOS - Sertoli cell-only syndrome; NOR — normal spermatogenesis; STD - seminiferous tubule diameter; TM - tubular membrane thickness; AFIS - areal fraction of intertubular spaces; LC — Leydig cells; ${ }^{a} \mathrm{p}<0.001$; SCOS vs. NOR (Mann-Whitney U test)
Table 2. Comparison of serum hormonal profile between SCOS and NOR groups

\begin{tabular}{|l|c|c|}
\hline \multirow{2}{*}{} & \multicolumn{1}{|c|}{$\begin{array}{c}\text { SCOS } \\
\mathbf{n}=\mathbf{4 0}\end{array}$} & $\begin{array}{c}\text { NOR (control) } \\
\mathbf{n = 1 5}\end{array}$ \\
\cline { 2 - 3 } & \multicolumn{2}{|c|}{ Median $(2.5-97.5$ percentile) } \\
\hline FSH $[\mathrm{mIU} / \mathrm{mL}]$ & $\mathbf{1 9 . 9}(\mathbf{7 . 1 - 3 4 . 4})^{\mathbf{a}}$ & $3.4(1.8-6.4)$ \\
\hline $\mathrm{LH}[\mathrm{mIU} / \mathrm{mL}]$ & $\mathbf{7 . 1}(\mathbf{2 . 2 - 2 6 . 3})^{\mathbf{a}}$ & $4.2(2.4-6.4)$ \\
\hline Testosterone $(\mathrm{T}) \mathrm{nmol} / \mathrm{L}$ & $14.6(7.8-27.4)$ & $13.2(8.5-25.7)$ \\
\hline T/LH ratio & $2.3(0.3-5.3) \mathrm{a}$ & $3.8(2.3-6.6)$ \\
\hline
\end{tabular}

SCOS - Sertoli cell-only syndrome; NOR — normal spermatogenesis; ${ }^{a} \mathrm{p}-<0.001-\operatorname{SCOS} v s$. NOR (Mann-Whitney U test)

Table 3. Spearman's rank correlations $\left(\mathrm{r}_{\mathrm{s}}\right)$ between morphometric features, hormone values and parameters of Leydig cell dysfunction in all subjects, SCOS and NOR groups

\begin{tabular}{|c|c|c|c|c|}
\hline & \multicolumn{4}{|c|}{ Total } \\
\hline $\mathrm{n}=\mathbf{5 5}$ & $\operatorname{STD}[\mu \mathrm{m}]$ & $\mathbf{T M}[\mu \mathbf{m}]$ & AFIS (\%) & LC-score \\
\hline $\mathrm{FSH}[\mathrm{mIU} / \mathrm{mL}]$ & $-0.61^{c}$ & $0.53^{\mathrm{c}}$ & $0.53^{\mathrm{c}}$ & $0.50^{c}$ \\
\hline $\mathrm{LH}[\mathrm{mIU} / \mathrm{mL}]$ & $-0.30^{c}$ & $0.37^{\mathfrak{c}}$ & $0.46^{\mathrm{c}}$ & $0.47^{\mathfrak{c}}$ \\
\hline Testosterone $(\mathrm{T})[\mathrm{nmol} / \mathrm{L}]$ & -0.01 & -0.10 & -0.01 & 0.19 \\
\hline $\mathrm{T} / \mathrm{LH}$ ratio & $0.22^{\mathrm{a}}$ & $-0.34^{c}$ & $-0.42^{c}$ & $-0.26^{b}$ \\
\hline \multirow[t]{2}{*}{ LC-score } & $-058^{c}$ & 0.21 & $0.40^{c}$ & - \\
\hline & \multicolumn{4}{|c|}{ NOR (control) } \\
\hline $\mathrm{n}=\mathbf{1 5}$ & $\operatorname{STD}[\mu \mathbf{m}]$ & $\mathbf{T M}[\mu \mathbf{m}]$ & AFIS (\%) & LC-score \\
\hline $\mathrm{FSH}[\mathrm{mIU} / \mathrm{mL}]$ & 0.17 & -0.06 & $0.53^{\mathrm{a}}$ & -0.33 \\
\hline $\mathrm{LH}[\mathrm{mIU} / \mathrm{mL}]$ & -0.51 & 0.05 & 0.21 & 0.15 \\
\hline Testosterone $(\mathrm{T})[\mathrm{nmol} / \mathrm{L}]$ & -0.16 & -0.39 & 0.26 & 0.02 \\
\hline $\mathrm{T} / \mathrm{LH}$ ratio & 0.33 & -0.34 & 0.30 & 0.09 \\
\hline \multirow[t]{2}{*}{ LC-score } & -0.40 & 0.01 & -0.04 & - \\
\hline & \multicolumn{4}{|c|}{$\operatorname{SCOS}$} \\
\hline $\mathrm{n}=\mathbf{4 0}$ & $\operatorname{STD}[\mu \mathrm{m}]$ & $\mathbf{T M}[\mu \mathbf{m}]$ & AFIS (\%) & LC-score \\
\hline $\mathrm{FSH}[\mathrm{mIU} / \mathrm{mL}]$ & -0.19 & 0.17 & $0.41^{\mathrm{a}}$ & $0.40^{\mathrm{a}}$ \\
\hline $\mathrm{LH}[\mathrm{mIU} / \mathrm{mL}]$ & -0.12 & 0.31 & $0.37^{\mathrm{a}}$ & $0.40^{\mathrm{a}}$ \\
\hline Testosterone $(\mathrm{T})[\mathrm{nmol} / \mathrm{L}]$ & -0.015 & -0.04 & -0.05 & 0.17 \\
\hline $\mathrm{T} / \mathrm{LH}$ ratio & 0.02 & -0.25 & $-0.36^{a}$ & -0.19 \\
\hline LC-score & $-0.48^{c}$ & 0.06 & 0.28 & - \\
\hline
\end{tabular}

SCOS — Sertoli cells only syndrome; NOR — normal spermatogenesis; STD — seminiferous tubule diameter; TM — tubular membrane thickness; AFIS — areal fraction of intertubular space; LC - Leydig cells; ${ }^{\mathrm{a}} \mathrm{p}<0.05 ;{ }^{\mathrm{b}} \mathrm{p}<0.01 ;{ }^{\mathrm{c}} \mathrm{p}<0.001$

correlations between LC-score and morphometric features in control group, while in SCOS LC-score negatively correlated with STD $(p<0.001)$ but not with AFIS or TM; however, the correlation between
AFIS and LC-score was close to statistical significance $(\mathrm{p}<0.056)$ (Table 3). Additionally, STD correlated negatively with AFIS $(r=-0.61, p<0.001)$ in the whole group and this association was also noticed in 
SCOS group $(r=-0.43, p<0.002)$, but not in the NOR group.

\section{Discussion}

In the present study we performed histological evaluation of testicular tissue with the pattern of SCOS and normal spermatogenesis focusing on detailed assessment of morphometric features of seminiferous tubules and intertubular space, as well as Leydig cell function. Moreover, we looked for associations between analyzed histological parameters and hormonal profile of the subjects.

As expected, the majority of our SCOS subjects had evident signs of testicular impairment presented by increased FSH and LH serum levels. We did not observed any abnormal levels of $\mathrm{T}$ when compared with men presenting normal spermatogenesis. Some earlier studies reported decreased serum levels of $T$ in men with infertility; however, in most of those studies the patients were recruited by their seminal parameters or fertility status $[14,24,25]$. Similarly to our results, the decrease in T levels was not found in some other studies, where the subjects were selected and grouped according to histological pattern of testicular biopsy $[7,12,16,26]$. The observed discrepancies may be explained by the fact that there is an extensive overlap between fertile and infertile men hormones' levels which may mask, to some extent, the differences between studied groups depending on selection criteria. Moreover, it appears that in some cases a type of control group may also be the reason for the discrepancies (seminal normozoospermia vs obstructive azoospermia with normal spermatogenesis in histological evaluation) [12]. We cannot also exclude that our group of patients, similarly to those in other histological studies mentioned above, is too small to reveal some minor differences between groups, which have been shown in larger populations [14].

However, despite the lack of differences in T levels between groups in the present study, we observed prominent decrease in T/LH ratio in SCOS group. This finding is in line with previous observations that impaired spermatogenesis is associated with decreased T/LH ratio, which is believed to be a result of Leydig cell dysfunction manifested by increased LH level and low-normal or decreased T level [7, 14-16, 24, 26-28].

It is well documented, that in the testes with disturbed spermatogenesis the increase in Leydig cell number may be observed $[7,12,15]$. There is evidence from animal models that increased number and impaired function of Leydig cells present in adulthood are the result of disturbed testicular organogenesis due to exposure to endocrine disruptors during fetal life $[29,30]$. Thus, it has been suggested that in some of the infertile men the impaired function of Leydig cells as well as their hyperplasia may be symptoms of testicular dysgenesis $[14,15]$.

Apart from the increased number of Leydig cells and the hormonal symptoms of their functional impairment, features of disturbed testicular organogenesis may be also observed [19, 31, 32]. In the present study we have shown that morphometric features of testicular dysgenesis were present in $25 \%$ of testes with SCOS. The incidence of decreased STD or increased AFIS were the most frequent and constituted more than $60 \%$ of all cases and in $43 \%$ they appeared concomitantly.

It was shown previously that the degree of spermatogenic impairment correlates with the prevalence of dysgenetic features such as decreased STD, increased TM, AFIS and increased number of Leydig cells [19]. We observed that the increased TM was seen in almost half of the testes with SCOS. The results are in line with previous studies reporting that impaired spermatogenesis is associated with alterations of TM thickness due to increased accumulation of extracellular matrix and that the degree of the pathology correlates well with disturbances of spermatogenesis [33-36]. There are reports that thickening of the lamina propria is not secondary to germ cell loss and it seems to be always associated with the maturation of Sertoli cells, like in human cryptorchid testes or in Klinefelter syndrome $[37,38]$. In dysgenetic testes preserved until adulthood the thickness of TM increases with the advancing age, while STD remains at the pre-pubertal level [19]. In cryptorchid testes the thickening of TM was observed already in 1-3-year-old boys, and it was associated with the inhibited maturation and disturbed functional relationships between Sertoli, Leydig and peritubular cells $[39,40]$. The thickening of TM was also reported in patients suffering from seminoma, varicocele, orchitis or cancer of the prostate [35, 38, 41].

We also found increased point value of LC-score in SCOS in comparison with NOR group. Moreover, LC-score correlated positively with LH serum levels and negatively with $\mathrm{T} / \mathrm{LH}$ ratio (when considered all subjects), what suggests a possible impairment of Leydig cell function, in line with previous reports [7, 12, 15]. It was suggested that impairment of spermatogenesis and Leydig cell function might reflect disturbed paracrine communication between the seminiferous epithelium and the Leydig cells, triggered by distorted function of the seminiferous epithelium, specifically Sertoli cells. However, it cannot be excluded that the parallel impairment of spermatogenesis and Leydig cells may reflect a congenital dysfunction of both 
compartments caused by testicular dysgenesis during fetal/infant development [14]. It is hypothesized that the increased number of Leydig cells per clusters in biopsies with impaired spermatogenesis may be the result of smaller STD and thus 'shrinkage' of tubular compartment resulting in regrouping of Leydig cell to form larger cluster [15]. In such situation we should expect that concomitantly with decreased STD due to the impairment of spermatogenesis an increased AFIS might be seen with increased Leydig cell number. In fact, in majority of our SCOS biopsies (81\%) presenting decreased STD and increased AFIS, we found an abnormal LC-score, which may support this hypothesis. However, there is still $19 \%$ of the SCOS biopsies where despite of decreased STD and increased AFIS the LC-score was normal. However, there is another possible explanation of increased Leydig cell number per cluster present in testes with impaired spermatogenesis. One can assume that it may be the result of prolonged proliferation of these cells during development caused probably by a lack of paracrine communication between impaired seminiferous epithelium and Leydig cells, with the secondary LH increase causing hyperstimulation of LCs [15]. Indeed, we observed that there are still some biopsies $(40 \%)$ where despite increased LC-score only one from the morphometric parameters (AFIS or STD) was abnormal, suggesting that in these cases the formation of larger cluster of Leydig cells might not be connected with 'shrinkage' of tubular compartment. Moreover, we found that in all cases the LC-score negatively correlated with STD and, consequently, positively with AFIS. However, in SCOS group only the correlation between STD and LC-score was consistently observed. It may suggest that in some of the SCOS biopsies the presence of wide intertubular space may be an independent feature of disturbed testicular organogenesis. In addition, the presence of higher AFIS correlated positively with FSH levels in both study groups, while the positive correlation with $\mathrm{LH}$ and negative with $\mathrm{T} / \mathrm{LH}$ was observed only in SCOS group.

In conclusion, we have shown that substantial number of testes from subjects with SCOS presented abnormal morphometric features which are recognized as the signs of testicular dysgenesis. Additionally, the finding of increased number of Leydig cells simultaneously with abnormal T/LH ratio suggests impaired function of these cells. Increased serum levels of $\mathrm{LH}$, and also FSH, may reflect Leydig cells dysfunction. It seems that reproductive hormones levels reflect also the condition of testicular structure, and that FSH may be related to the changes in intertubular space area independently of impaired Leydig cell function.

\section{Acknowledgments}

This study was supported by grants funded by the National Science Centre, Poland (Grant number UMO-2014/13/B/NZ4/01198) and the Medical University of Lodz, Poland (Grant number: 503/1-08903/503-11-002).

\section{Competing interests}

The authors declare that they have no competing interests.

\section{Authors' contributions}

DA wrote the draft of the manuscript; performed histological analysis of the biopsy, statistical analysis and interpretation of the results (a part of the results presented in the article were used in DA's Master Thesis, Medical University of Lodz; Faculty of Pharmacy; Department of Laboratory Medicine); JSH conceived and designed the study, analyzed clinical data, contributed in interpretation of the results, critically revised the manuscript; KM gave an intellectual content in preparing the manuscript; RWJ conceived and designed the study, performed histological analysis of the biopsy, statistical analysis and interpretation of the results, critically revised the manuscript. All authors read and approved the final manuscript.

\section{References}

1. Jungwirth A, Giwercman A, Tournaye H, et al. European Association of Urology Guidelines on Male Infertility: The 2012 Update. Eur Urol. 2012; 62(2): 324-332, doi: 10.1016/j. eururo.2012.04.048, indexed in Pubmed: PMID: 22591628.

2. Krausz C. Male infertility: Pathogenesis and clinical diagnosis. Best Pract Res Clin Endocrinol Metab. 2011; 25(2): 271-285, doi: 10.1016/j.beem.2010.08.006, indexed in $\mathrm{Pu}-$ bmed: 21397198.

3. Walczak-Jedrzejowska R, Wolski J, Slowikowska-Hilczer $\mathrm{J}$. The role of oxidative stress and antioxidants in male fertility. Cent European J Urol. 2013; 65: 60-67, doi: 10.5173/ ceju.2013.01.art19, indexed in Pubmed: 24578993.

4. Gill K, Jakubik J, Kups M, et al. The impact of sedentary work on sperm nuclear DNA integrity. Folia Histochem Cytobiol. 2015, doi: 10.5603/fhc.a2019.0002, indexed in $\mathrm{Pu}-$ bmed: 30869154.

5. Shi H, Liu J, Zhu P, et al. Expression of peroxiredoxins in the human testis, epididymis and spermatozoa and their role in preventing $\mathrm{H} 2 \mathrm{O} 2$-induced damage to spermatozoa. Folia Histochem Cytobiol. 2018; 56(3): 141-150, doi: 10.5603/fhc. a2018.0019, indexed in Pubmed: 30187908.

6. Rajert-De Me, Grigor K, Skakkebaek N. Histoathological Evaluation of Testicular Biosy. In: Lenzi A, Simoni M, Huhtaniemi I, editors. Endocrinology of the Testis and Male Reroduction. Endocrinology. Cham, Switzerland: Sringer; 2017: 623-642. 
7. Lardone MC, Piottante A, Valdevenito R, et al. Histological and hormonal testicular function in oligo/azoospermic infertile men. Andrologia. 2012; 45(6): 379-385, doi: 10.1111/ and.12026, indexed in Pubmed: 23013062.

8. Halder A, Jain M, Kumar P. Primary Testicular Failure: An Overview. J Clin Diag Res. 2015; 3: 1-5, doi: 10.4172/2376$0311.1000 \mathrm{e} 105$.

9. Jain M, Kumar P, Iyer V, et al. Primary Testicular Failure. Basics of Human Andrology. 2017: 417-436, doi: 10.1007/978981-10-3695-8_24.

10. Cheng Y, Chung C, Chen C, et al. Differential expression of microRNAs and their messengerRNA targets in men with normal spermatogenesis versus Sertoli cell-only syndrome. Urol Sci. 2017; 28(1): 42-49, doi: 10.1016/j.urols.2016.03.002.

11. Stouffs K, Gheldof A, Tournaye H, et al. Sertoli Cell-Only Syndrome: Behind the Genetic Scenes. BioMed Res Int. 2016; 2016: 1-7, doi: 10.1155/2016/6191307, indexed in $\mathrm{Pu}$ bmed: 26925412 .

12. Lardone MC, Castillo P, Valdevenito R, et al. P450-aromatase activity and expression in human testicular tissues with severe spermatogenic failure. Int J Androl. 2010; 33: 650-660, doi: 10.1111/j.1365-2605.2009.01002.x, indexed in Pubmed: 19906189.

13. Matsumoto AM, Bremner WJ, et al. Testicular disorders. In: Melmed S, Polonsky KS, Larsen PR, , editors. Williams Textbook of Endocrinology. 13 ed: Elsevier; 2017: 694-708.

14. Andersson AM, J rgensen N, Frydelund-Larsen L, et al. Impaired Leydig Cell Function in Infertile Men: A Study of 357 Idiopathic Infertile Men and 318 Proven Fertile Controls. J Clin Endocrinol Metab. 2004; 89(7): 3161-3167, doi: 10.1210/jc.2003-031786, indexed in Pubmed: 15240588.

15. Holm M, Meyts ERD, Andersson AM, et al. Leydig cell micronodules are a common finding in testicular biopsies from men with impaired spermatogenesis and are associated with decreased testosterone/LH ratio. J Pathol. 2003; 199(3): 378 -386, doi: 10.1002/path.1309, indexed in Pubmed: 12579540.

16. Lardone MC, Argandona F, Florez M, et al. Overexpression of CYP19A1 aromatase in Leydig cells is associated with steroidogenic dysfunction in subjects with Sertoli cell-only syndrome. Andrology. 2017; 5: 41-48, doi: 10.1111/andr.12289, indexed in Pubmed: 27769104.

17. Toppari J, Skakkebk N. Sexual differentiation and environmental endocrine disrupters. Baillieres Clin Endocrinol Metab. 1998; 12(1): 143-156, doi: 10.1016/s0950-351x(98)80529-6, indexed in Pubmed: 9890066.

18. Sharpe R. The ,oestrogen hypothesis'- where do we stand now?1. Int J Androl. 2003; 26(1): 2-15, doi: 10.1046/j.13652605.2003.00367.x, indexed in Pubmed: 12534932.

19. Guminska A, Oszukowska E, Kuzanski W, et al. Less advanced testicular dysgenesis is associated by a higher prevalence of germ cell neoplasia. Int J Androl. 2009; 33(1): e153-e162, doi: 10.1111/j.1365-2605.2009.00981.x, indexed in Pubmed: 19719533.

20. Hoei-Hansen C, Holm M, Meyts ERD, et al. Histological evidence of testicular dysgenesis in contralateral biopsies from 218 patients with testicular germ cell cancer. J Pathol. 2003; 200(3): 370-374, doi: 10.1002/path.1372, indexed in Pubmed: 12845633.

21. Holstein AF, Roosen-Runge EC, Schirren CS. The testis biopsy. In: Holstein AF, Roosen-Runge EC, Schirren CS, editors. llustrated Pathology of Human Testes. Berlin: Grosse Verlag; 1988: 58-76.

22. Weinbauer GF, Gromoll J, Simoni M, et al. Physiology of testicular function. Andrology. Male Reroductive Health and Dysfunction. Berlin, Heidelberg, New York.: Sringer Verlag; 2010: 25-60.

23. Guminska A, Slowikowska-Hilczer J, Kuzanski W, et al. Features of impaired seminiferous tubule differentiation are associated with germ cell neoplasia in adult men surgically treated in childhood because of cryptorchidism. Folia Histochem Cytobiol. 2007; 45 : S163-168, doi: https://www.ncbi.nlm. nih. gov/pubmed/18292827, indexed in Pubmed; 18292827.

24. Giagulli VA, Vermeulen A. Leydig cell function in infertile men with idiopathic oligospermic infertility. J Clin Endocrinol Metab. 1988; 66(1): 62-67, doi: 10.1210/jcem-66-1-62, indexed in Pubmed: 2891722.

25. Bruno B, Villa S, Properzi G, et al. Hormonal and seminal parameters in infertile men. Andrologia. 2009; 18(6): 595-600, doi: 10.1111/j.1439-0272.1986.tb01837.x, indexed in Pubmed: 3101547.

26. Parada-Bustamante A, Molina C, Valencia C, et al. Disturbed testicular expression of the estrogen-metabolizing enzymes CYP1A1 and COMT in infertile men with primary spermatogenic failure: possible negative implications on Sertoli cells. Andrology. 2017; 5(3): 486-494, doi: 10.1111/andr.12346, indexed in Pubmed: 28334509.

27. Glass AR, Vigersky RA. Leydig cell function in idiopathic oligospermia. Fertil Steril. 1980; 34: 144-148, doi: https:// www.ncbi.nlm.nih. gov/pubmed/6773819, indexed in $\mathrm{Pu}-$ bmed; 6773819 .

28. Lardone MC, Argando a F, Lorca M, et al. Leydig cell dysfunction is associated with post-transcriptional deregulation of CYP17A1 in men with Sertoli cell-only syndrome. MHR: Basic science of reproductive medicine. 2018; 24(4): 203-210, doi: 10.1093/molehr/gay006, indexed in Pubmed: 29438521.

29. Fisher JS. Human ,testicular dysgenesis syndrome': a possible model using in-utero exposure of the rat to dibutyl phthalate. Hum Reprod. 2003; 18(7): 1383-1394, doi: 10.1093/humrep/ deg273, indexed in Pubmed: 12832361.

30. Foster P. Effects of phthalate esters on the developing reproductive tract of male rats. Hum Reprod Update. 2001; 7(3): 231-235, doi: 10.1093/humupd/7.3.231, indexed in Pubmed: 11392369.

31. Chemes H, Muzulin P, Venara M, et al. Early manifestations of testicular dysgenesis in children: pathological phenotypes, karyotype correlations and precursor stages of tumour development. APMIS. 2003; 111(1): 12-24, doi: 10.1034/j.16000463.2003.1110104.x, indexed in Pubmed: 12760349.

32. Cools M, Aerde Kv, Kersemaekers AM, et al. Morphological and Immunohistochemical Differences between Gonadal Maturation Delay and Early Germ Cell Neoplasia in Patients with Undervirilization Syndromes. J Clin Endocrinol Metab. 2005; 90(9): 5295-5303, doi: 10.1210/jc.2005-0139, indexed in Pubmed: 15998778.

33. Sato Y, Nozawa S, Iwamoto T. Study of spermatogenesis and thickening of lamina propria in the human seminiferous tubules. Fertil Steril. 2008; 90(4): 1310-1312, doi: 10.1016/j. fertnstert.2007.10.019, indexed in Pubmed: 18304550.

34. Albrecht M. Insights into the nature of human testicular peritubular cells. Ann Anat. 2009; 191(6): 532-540, doi: 10.1016/j. aanat.2009.08.002, indexed in Pubmed: 19765961.

35. Volkmann J, Muller D, Feuerstacke C, et al. Disturbed spermatogenesis associated with thickened lamina propria of seminiferous tubules is not caused by dedifferentiation of myofibroblasts. Hum Reprod. 2011; 26(6): 1450-1461, doi: 10.1093/humrep/der077, indexed in Pubmed: 21467201.

36. Liu Y, Zhu Y, Di L, et al. Raman spectroscopy as an ex vivo noninvasive approach to distinguish complete and incom- 
plete spermatogenesis within human seminiferous tubules. Fertil Steril. 2014; 102(1): 54-60.e2, doi: 10.1016/j.fertnstert.2014.03.035, indexed in Pubmed: 24767690.

37. Paniagua R, Martinez-Onsurbe P, Santamaria L, et al. Quantitative and ultrastructural alterations in the lamina propria and Sertoli cells in human cryptorchid testes. Int J Androl. 1990; 13(6): 470-487, doi: 10.1111/j.1365-2605.1990.tb01054.x, indexed in Pubmed: 1982882.

38. Martin R, Santamaría L, Nistal M, et al. The peritubular myofibroblasts in the testes from normal men and men with Klinefelter's syndrome. A quantitative, ultrastructural, and immunohistochemical study. J Pathol. 1992; 168(1): 59-66, doi: 10.1002/path.1711680111, indexed in Pubmed: 1453270.
39. Hadziselimovic F. Cryptorchidism. Ultrastructure of normal and cryptorchid testicular development. Berlin, Heidelberg, New York: Springer Verlag; 1977.

40. Müller J, Skakkebaek N. Abnormal Germ Cells in Maldescended Testes: A Study of Cell Density, Nuclear Size and Deoxyribonucleic Acid Content in Testicular Biopsies from 50 Boys. J Urol. 1984; 131(4): 730-733, doi: 10.1016/s00225347(17)50602-3, indexed in Pubmed: 6142966.

41. Santoro G, Romeo C, Impellizzeri P, et al. Ultrastructural and immunohistochemical study of basal lamina of the testis in adolescent varicocele. Fertil Steril. 2000; 73(4): 699-705, doi: 10.1016/s0015-0282(99)00611-1, indexed in Pubmed: 10731528.

Submitted: 24 February, 2020

Accepted after reviews: 12 May, 2020

Available as AoP: 2 June, 2020 